\section{THE ECLIPSE EXPEDITION}

$A \mathrm{~S}$ we intimated last week, the weather was more or less unfavourable at nearly all the stations for the observation of the Total Eclipse of Dec. 22nd. We give, in another column, an account of the preparations made by the Sicilian department of the Expedition, received by us. The following account of the results obtained at some of the other stations is compiled chiefly from reports furnished to the Times and Daily Nezes.

From Cadiz we have an interesting account by the Rev. S. J. Perry, as follows:-

"The situation of San Antonio is found to be lat. $36^{\circ}$ $37^{\prime} 13^{\prime \prime} \mathrm{N}$., long. $24^{\prime} 15^{\prime \prime} \mathrm{W}$. of Greenwich. Time signals were daily received from the San Fernando Observatory, and all our chronometers carefully rated by Capt. Toynbee. Our thirteen observers were distributed as follows: $\mathrm{Mr}$. Moulton, of Christ's College, Cambridge, with Mr. Baines, of Oxford, were to observe with the polariscope at Sanlucar, the extreme $W$. point on the Spanish central line of totality, and I2 miles N.W. of San Antonio. Near Xeres, 5 miles N.E. of San Antonio, were stationed Mr. P. Naftel, for an eye sketch of the corona, Mr. F. C. Penrose to sketch the same as seen through a telescope, and Mr. Abbay, of Wadham College, Oxford, to observe with the spectroscope. Mr. W. Smyth sketched near Arcos, 17 miles E.N.E. of San Antonio, using a telescope of the same aperture as that of Mr. Penrose. The rest of the observers remained at San Antonio. At this station the spectroscopic observers were Capt. Maclear, R.N., and myself, assisted by Mr. Hostage. Polarisation was to be observed by Mr. Hudson, of St. John's, Cambridge, and Mr. Ladd, optician; and an eye sketch of the corona to be made by Mr. Browne, of Oxford. The weather has been unexceptionally bad ever since our arrival, the only fine day being the 2 Ist. Our observers were therefore spread out as much as possible, in hopes of not failing altogether on account of bad weather:. The results justified our anticipations. The fine weather of the 2 Ist lasted but a day, and at two $A M$. of the 22 nd the clouds and rain returned. At San Antonio a break only came some $4^{85}$ after first contact, when a distinct notch was observed on the solar disc. This break was only a change from thick cloud to thin cirrhus, but we were enabled to observe the time of contact of the limb of the moon with several of the more remarkable solar spots. In the north the sky was partially clear, but in the south no part of the heavens was free from cloud. A very striking change of light on the landscape was noticed when little more than threefourths of the solar disc was covered, and a chill was felt by all. The thermometer observed by Capt. Toynbee fell $3^{\circ} \mathrm{F}$. from the commencement to totality, and rose again $1.7^{\circ}$ before the "end of the Eclipse. The barometer was falling rapidly all the time of the Eclipse, and also afterwards, at the rate of 0.04 in. an hour. The wind was W. by N. true. During totality it lulled, but freshened afterwards with very heavy rain. The moment of totality approached, and no chance remained of even a momentary break in the thin cirrhus that enveloped the sun, and obscured most of the southern heavens. As the crescent became thinner, the cusps were observed first to be drawn out a length of several minutes, and then blunted; the wellknown Baily beads were formed, and the corona burst forth more than $20^{5}$ before totality. Viewed through a telescope of very moderate dimensions the spectacle was grand, but the cirrhus clouds destroyed almost all the grandeur of the effect for the naked eye. The red prominences were numerous, but hone apparently very remarkable; Mr. W. H. Browne, of Wadham College Oxford, considers their colour to have been of a bright yellowish red tint. The same observer notices that the corona was perfectly free from striation, outline distinct, and approximately quadrilateral, but extending farthest in the direction of first contact. The brightest part of the corona appeared to the unassisted eye to be scarcely more than one-tenth of the sun's diameter, fading rapidly when one-fifth, but being still clearly visible at seveneighths. Some observed two curved rays, but the general appearance was that of a diffuse light interrupted in four places distinctly, and in a fifth faintly, by dark intervals. The corona was white, and rendered faint by the clouds. The darkness was never sufficient to prevent sketching with comfort without the aid of a lamp. Venus alone was visible. Totality ended by the formation of Baily's beads, and the corona was visible to the naked eye $15^{\circ}$ or $16^{\mathrm{s}}$ after totality. The coroua was seen for $2^{\mathrm{m}} 5 \mathrm{O}^{\mathrm{s}}$, totality lasting less than $2^{\mathrm{m}} 1 \mathrm{O}^{\mathrm{s}}$. The clouds obscuring the sun appear to have destroyed almost all chance of detecting any except atmospheric polarisation. Mr. Ladd remarked that the polarisation was stronger on the corona than on either the moon's surface or the cloudy sky.

"No report has as yet been received of the polarisation observations at Sanlucar. The observations with the spectroscope were also greatly interfered with by the cirrhus, and the best instrument was rendered entirely useless. The intensity of the light from the corona, as seen through the clouds, could not, I think, have been more than one-eighth of that of the bright moon, if so much, and, consequently, I was unable to detect the faintest trace of light through the three compound prisms I was using. The chances of observing satisfactorily, considering the state of the sky, were greatly diminished by the largeness of the direct image given by the Cassegrain I was compelled to use. Knowing that an unfavourable sky would render observations with a powerful spectroscope quite impracticable, I desired Captain Maclear to observe with a small direct vision Browning spectroscope, attached to a four-inch achromatic by fones, mointed equatorially. The slit was placed radial at the centre of the east limb, and close to it, and immediately totality commenced the ordinary solar spectrum was replaced by a faint diffused light, and bright lines near C, D, b (or E), and F. No absorption bands. The slit was then removed to a distance about $8^{\prime}$ from the limb, and the same lines remained visible. The centre of the moon was next tried, and the bright lines were still seen, but only half as strong as before. The slit was then placed $8^{\prime}$ outside the W. limb, and the lines became as strong as before, and were $C$, D, one three-quarters of the distance from $D$ to $E$, and another half way between $E$ and $F$. Lastly, placing the slit near the sun (on a prominence) two new green lines, and a very brilliant line beyond $F$, were added to those already visible, but the line near $\mathrm{E}$ may have disappeared. The lines seen on the moon were, I suppose, due to the diffusive power of the cirrhus clouds; and the same may perhaps be true of the apparent coronal lines.

"Mr. Abbay, observing at Xeres with a spectroscope of two prisms of $45^{\circ}$, belonging to Professor Young, saw the bright lines $\mathrm{C}, \mathrm{D}, \mathrm{F}$; and afterward F, and a line rather more bright than $F$, at some distance on the less refrangible side of $B, C$ not noticed then. These two observations were, I think, taken at points external to the prominences, but I cannot at present speak with certainty, as no note to that effect is entered in the memorandurn I received. A comparison of these observations with those of other observers more favoured than ourselves will doubtless lead to valuable results. Shortly after totality the clouds thickened still more, and nothing further could be observed."

The view of the Eclipse obtained near Arcos is described as very magnificent; a sketch was made there by $\mathrm{Mr}$. Warrington Smyth. At the American station near Xeres there was a break in the clouds, which lasted somewhat more than half the totality. But Lord Lindsay's party was the most favoured in this country, having seen the sun through a rent in the clouds for five minutes, and this time embracing the whole of totality. Mr, O. Airy and 
Mr. Hammond, of Trinity College, Dublin, observed at San Antonio, and were kindly assisted by Lieutenant P. H. Worgan and Mr. T. H. Atkinson, of H.M.S. Lee.

Another correspondent, from Cadiz, writes to say that Lord Lindsay succeeded in taking several excellent photographs from a vineyard belonging to $\mathrm{Mr}$. Campbell, half way between Port St. Mary's and San Lucar.

The American party at Xeres saw the totality for about a minute.

From Gibraltar, Mr. R. M. Parsons sends the following report :-

"'The party that left England for the purpose of observing the Total Eclipse of the sun at Gibraltarnamely, Messrs. Carpmael, Gordon, Lewis, Buckingham, Beasley, Harrison, Anson, Abbatt, Talmage, and myself - disembarked from Her Majesty's ship Urgent on the I4th Dec., and all but the three last-mentioned proceeded to Estepona, a village in Spain, about thirty miles northeast from Gibraltar, and situated in the central line of totality. By this division of the party an additional chance was afforded of observing the phenomenon in case of bad weather, and Estepona offered the advantage of some 13 longer time of total obscuration than Gibraltar, a condition very desirable for the particular class of observations required by some of the party. The weather at Gibraltar was wet and cloudy almost from the time we landed until the day before the Eclipse, when a strong breeze W. by $\mathrm{N}$ gave a beautifully clear sky, which lasted till about midnight. Mr. Talmage, the director of the Leyton Obser vatory, and I, determined to observe from the Moorish Castle if the atmospheric conditions of the 2ist should hold good on the 22 nd ; but I arranged to receive constant telegrams of the weather from Europa Point on the morning of the 22nd, and conveyance was provided to move the instruments at the latest practicable period, in case any other position afforded better chances of success. Mr. Talmage was to take angular measurements of Saturn, if seen through the corona, Mr. Abbatt to sketch the corona, and I was to examine it with a polariscope. The westerly wind increased in force on the 22nd, but brought with it scud and dense clouds across the Bay from the Spanish mountains; everywhere these clouds were massed in the sky, separated by small intervals of hazy blue. The last telegram was received from Europa at a quarter-past eleven, forty minutes before commencement of totality, stating 'sky quite overcast, heavy clouds moving south-east, sun harily visible.' 'This, together with the circumstance that the Rock did not appear to affect the clouds which were moving under the influence of a westerly wind, led me to conclude that the chances of good vision were equal at any position on the Rock. After waiting on the Line Wall for these telegrams, at which place I failed to observe the first contact, while Mr. Talmage failed in the same endeavour at the Moorish castle, I joined him there, leaving Mr. Abbatt with his telescope erected on the flat roof of a house about a quarter of a mile west of the castle. The cloud which caps the Rock of Gibraltar, the summit of which is $1,396 \mathrm{it}$. above the sea, during east winds, or Levanters, leaves this comparatively low level clear. About $30^{5}$ before the commencement of totality, a hazy blue break in the clouds enabled us to see the thin bright crescent of the sun, but unfortunately this patch of hazy blue sky, which favoured others for a few seconds, came a little too early in front of our position, and it was followed by a dense cloud, behind which the entire phenomenon of totality was hidden from us. The darkness was considerable, but not so great as when I observed the Total Eclipse of 1860 , at Nisqually, in an unclouded sky. Then a lamp was necessary to enable a white-faced pocket chronometer to be read; yesterday I could see the divisions distinctly at the distance of eight inches withput such aid. Mr. Abbatt had the good fortune to ste the corona and some red prominences, but only for about two seconds before they were lost in the same dense cloud; he estimated the breadth of the corona at about a sixth part of the moon's radius. Professor Newcomb, of the United States' Expedition, was able to see all four contacts, and to take several measurements that were necessary for the work he has in hand; he also caught a glimpse of the corona, but says he could make no use of it.

"Mr. Lewis states that the party at Estepona only saw the total phase through a break in the clouds for about $10^{s}$ or $15^{5}$, when it was covered by light cloud. Mr. Buckingham, at Estepona, states that they had there heavy rain; he could take no photographic pictures, but Mr. Carpmael had observed three bright lines in doubtful positions, and Mr. Lewis found the corona polarised; the rest of the party had negative results. Mr. Harrison, who was distant a mile from the others, did not see the total phase. Mr. Anson had not time at the moment to sketch what he saw, but probably may be able to do so from nemory, and $\mathrm{Mr}$. Fison, who had then joined the party, had no opportunity of obtaining satisfactory observations."

Mr. Abbatt reports :- "In no part did the corona or the prominence extend beyond I-8th or at most I-6th of the moon's radius beyond the limb. I thought the moon darker than the sky. I noticed four high red prominences-there were more, but when, for an instant, I took my eye off the telescope a dense black cloud had obscured everything till the narrowest streak of the sun appeared on the western side, and nothing but the ordinary phenomenon of a partial eclipse was to be seen. The darkness during totality was not so great as I expected it would be. Two stars were seen, one near the sun and the other overhead, but I can get no further information as to their exact position."

Another observer writes as follows:- "The eclipsed orb presented itself through a rent in the clouds not greater in area than ten times that of the disc of the moon's shadow. That part of the opening which was above the eclipsed orb was clear like the sun at twilight, and in it were visible to the naked eye the planets Venus, Mercury, and half a dozen stars. The remaining part was covered with a thin haze. The moon's shadow appeared to the eye, assisted by a somewhat weak binocular glass, to be a dark circular disc with an even boundary and of uniform shade. Within the corona, and touching the circumference of this shadow, appeared five or six spots of brilliant carmine, varying in form and size and at irregular distances apart. Two of these spots, or 'red flames,' as they are called, on the eastern side of the disc, and at about $55^{\circ}$ and $80^{\circ}$ respectively from the vertex, seemed decidedly the largest and most prominent; they were tongue-shaped, and protruded about $1-6$ th the width of the corona. In their neighbourhood the corona was brightest and widest. There, too, the rays of the corona appeared to be gathered more distinctly into groups than elsen here, faint shadows being visible between the groups. The corona consisted of brilliant rays of extremely faint prismatic hues; these rays at first sight appeared pretty evenly distributed all round, but closer examination seemed to detect the fact of there being bundles of rays in nearly regular groups. The width of the corpna was about $\mathrm{I}-8 \mathrm{th}$ the apparent diameter of the moon's shadow. It was very nearly concentric with the disc of the shadow; its boundary was well defined, but 'jagged ;' the perimeter, except opposite the two most prominent red flames abovementioned, where the boundary slightly protruded, was circular."

From Seville, we have a report from M. E. A. De Cosson:-

"The Eclipse began at IO.30 A.M. (Seville time). At I0.45 one-sixth of the sun's diameter was obscured; at II.I5 one-half; and at 12 the Eclipse was total. At I2.IO it began to rain, and the sun was lost to sight until the conclusion of the eclipse, which occurred at I.3O P.M. The eclipse was total for $70^{s}$ and the effect was 
very striking, the whole sky becoming of a lurid purple and very dark. The birds were hushed and frightened, and the charcoal burners' fires in the mountains, some five miles distant were plainly visible."

At Oran the weather appears to have been still more unpropitious than at the European stations. For the observations with the spectroscope, this section of the Expedition was provided with a 6-inch equatorial, of eight feet focal length, by Cooke, of York, lent by the Royal Observatory at Greenwich, to which was adapted an extremely ingenious recording spectroscope, the invention of Dr. Hug sins, who himself observed with it ; the management of the telescope devolving upon Captain Noble. A second smaller instrument, of 4 inches aperture, with a somewhat similar recording apparatus, was entrusted to Mr. W. Crookes, F.R.S., the Rev. F. Howlett attending to the telescope itself. The polariscopic observations were undertaken by Captain Salmond, R.E., and Lieutenant Collins, R.E.; the instrument of the former being attached to a telescope of about thirty inches focal length and $2 \frac{1}{2}$ inches aperture; that of the latter to another of 6 inches aperture. General observations, sketching of the corona, \&c., were to have been made by $\mathrm{Mr}$. Carpenter, of Greenwich Observatory, with an exquisite 3 -in. Dolland equatorial; by Mr. Hunter, with a 4-in. of rougher construction ; by Lieut. Wharton, R.N., of the Urgent, with a $2_{4}^{3}$ achromatic, mounted temporarily equatorially; by Admiral Ommaney, with a small table telescope ; by Lieut. Ommaney, R.E., with a binocular field-glass, on cards arranged for the purpose; and by the ship's officers generally, with such telescopes as they could command. The 6-in. and 4-in. equatorials were erected under a tent ; the rest were employed more or less in the open air. Prof. Tyndall had established himself on a neighbouring fort, some 500 or 600 yards from the rest of the party, with a 5 -in. telescope by Dallmeyer, which had been used by $\mathrm{Mr}$. Dela Rue at the Total Eclipse in Spain. His observations were to be of a general character.

The atmospheric conditions in Oran in December are exceedingly like those of a very wet and windy English autumn, the day of entering into port having been the only moderately fine one experienced at all. The wind particularly was tremendous. On the 2 ist the observatory tent was blown down, and it was only by great exertions that the instruments themselves were saved from destruction.

The morning of the 2 nd broke very doubtfully, heavy driving clouds obscuring the sun. The party were, however, all at their posts betimes, and arranged their various instruments long before the predicted instant of first contact. The clouds obscured the sun at this particular time ; but soon, through a rift in them, the dark limb of the moon was seen encroaching on the sun's disc. Observation after this became very trying, as it was only possible at distant intervals to glimpse the progress of the moon, as she gradually advanced in her path. Spectroscopic observation, or even polariscopic observation, was practically impossible. Finally a glimpse was caught of the sun some eight or nine minutes before totality as a very thin crescent, and then every chink and cranny in the clouds closed up, and one dense and impenetrable pall covered the earth. Nothing remained now but to go out of the tent and observe the effect in the open air. It was certainly very striking. As the moment of totality approached, the western sky turned of an awful livid purple, the clouds over head assuming a black tint. As the shadow swept over the earth, the eastern sky became obscured, while the western horizon lighted up like the grey dawn of a dull autumn morning. At no time, however, during the totality, was it difficult to see the seconds on the face of a watch. The light was that of a cloudy evening, about an hour after sunset. One curious effect was observed, the apparent contraction or closing in of the celestial vault. Speedily, however, the dawn in the

western horizon spread over the heavens; but the sun did not reappear again forat least half an hour after totality. M. Janssen, the French astronomer, who escaped, at the risk of his life, with his instruments in a balloon from Paris, was stationed on a mountain some seven miles from Oran. He can have seen nothing whatever of the phenomenon which he had braved so much to observe.

Another account from the same station states that the earlier stages of the Eclipse were seen and a photograph taken, but ten minutes before totality a dense bank of clouds came over the sun, which extinguished all hope, and rendered useless the laborious preparations of many weeks. M. Janssen was of course equally unsuccessful. Though the darkness was almost appalling as it rapidly increased up to the moment of totality, still the scene was deprived of a large part of its impressiveness by the dense mantle of cloud which concealed nearly the whole heavens.

\section{SOCIETIES AND ACADEMIES \\ LONDON}

Chemical Society, December I5.--Prof. Frankland, F.R.S., Vice-president, in the chair.-The following gentlemen were elected Fellows :-P. 'T. Atkinson, R. Koma, J. F. Stark. Mr. Perkin, F.R.S., read a paper "On some new Derivations of Coumarin." The author succeeded in obtaining the following new bodies :-

Dibromide of Coumarin

Dichloride of Coumarin

a Bromocoumarin

$\beta$

西

a Chlorocoumarin

$\beta$

a Dibromocoumarin

Tetrachlorocoumarin

Coumarilic acid

Bromocoumaric acid

Sulphocoumaric acid

Disulphocoumaric acid

Dibronide of Contmatin. -A solution of commarin in carbon di. sulphide is mixed with a similar solution of bromine, and the mixture, aiter leaving it to stand for' twelve hours, allowed to evaporate spontaneously. When dibromicle of coumarin is treated with an alcoholic solution of potassic iodide it becomes brown, and on evaporation deposits needles apparently consisting of a mixture of iodine and coumarin crystals, a Bromocounuarizt. A simple process for the preparation of Bromocaumarin is to decompose the dibromide of coumarin with alkalis, the following reaction taking place:-

$$
\underbrace{\mathrm{C}_{9} \mathrm{H}_{6} \mathrm{O}_{2} \mathrm{Br}_{2}}_{\text {Dibromide of coumarin. }}+\mathrm{KHO}=\underbrace{\mathrm{C}_{9} \mathrm{H}_{5} \mathrm{Br} \mathrm{O}_{2}}_{\text {Bromocoumarin. }}+\mathrm{K} \mathrm{Br}+\mathrm{H}_{2} \mathrm{O}
$$

a Bromocoumarin, when left in contact with cold alcoholic ammonia, decomposes with formation of ammonic bromide, and a non-crystalline sticky mass easy soluble in water. Heated with potassic hydrate it yields potassic bromide and a new acid. a Dibromocoumarin.-At a previous occasion $\mathrm{Mr}$ Perkin prepared this body by heating in a sealed tube to $140^{\circ} \mathrm{C}$. a mixture of one part of coumarin, two parts of bromine, and four or five parts of disulphide of carbon. He since found, however, that this process is greatly improved by the addition of iodine to the mixture, as it is then only necessary to heat the sealed tube for four or five hours in a bath of salt and water to complete the reaction. The fusing point of this substance is $183^{\circ} \mathrm{C}$. and not $174^{\circ} \mathrm{C}$. as had been previously given. $\beta$ Bromocoumarin.-The hydride of sodium bromosalicyl when submitted to the action of acetic anhydride, yields a quantity of hydride of bromosalicyl and a body which, when crystallised from alcohol, yields colourless flat prisms, the analysis of which showed it to be monobromocoumarin, $\mathrm{C}_{9} \mathrm{H}_{5} \mathrm{Br} \mathrm{O}_{2}$. It greatly differs in properties from the bromocoumarin previously described, its fusing point being $160^{\circ} \mathrm{C}$, or $50^{\circ}$ higher, and when boiled with alcoholic or aqueous potassic hydrate it does not decompose with formation of potassic bromide, but simply dissolves like ordinary coumarin. $\beta$ Dibromocoumarin.-On treating the hydride of sodium dibromosalicyl 